\title{
Childhood Hodgkin Lymphoma
}

National Cancer Institute

\section{Source}

National Cancer Institute. Childhood Hodgkin Lymphoma. NCI Thesaurus. Code C7714.

Hodgkin lymphoma occurring in childhood. 